\title{
The association between FTO gene polymorphism rs 9939609 and obesity is sex-specific in the population of PURE study in Poland
}

\author{
Aleksandra Zdrojowy-Wełna ${ }^{1, A-D, F}$, Grażyna Bednarek-Tupikowska ${ }^{1, A, C, E, F}$, Katarzyna Zatońska ${ }^{2, A-C, E, F}$, \\ Katarzyna Kolačkov ${ }^{1, B-D, F}$, Alicja Jokiel-Rokita ${ }^{3, C-F}$, Marek Bolanowski ${ }^{1, A, C, E, F}$ \\ ${ }^{1}$ Department of Endocrinology, Diabetes and Isotope Therapy, Wroclaw Medical University, Poland \\ 2 Department of Social Medicine, Wroclaw Medical University, Poland \\ ${ }^{3}$ Department of Pure and Applied Mathematics, Wroclaw University of Science and Technology, Poland \\ A - research concept and design; B - collection and/or assembly of data; C - data analysis and interpretation; \\ $D$ - writing the article; $E$ - critical revision of the article; $F$ - final approval of the article
}

Address for correspondence

Aleksandra Zdrojowy-Wełna

E-mail: aleksandra.zdrojowy-welna@umed.wroc.pl

Funding sources

Wroclaw Medical University Grant for Young Researchers (grant No. 158)

Conflict of interest

None declared

Received on February 12, 2019

Reviewed on March 12, 2019

Accepted on August 18, 2019

Published online on January 22, 2020

\begin{abstract}
Background. Fat mass and obesity-associated gene (FTO) polymorphism remains the strongest known genetic determinant of common obesity. However, its influence depends on ethnicity, and the FTO-mediated predisposition to other metabolic disturbances is questionable.

Objectives. The aim of our study was to evaluate the association between FTO rs 9939609 polymorphism and metabolic syndrome in a population of Prospective Urban Rural Epidemiology (PURE) study in Poland.

Material and methods. We enrolled 1,097 participants of the PURE study (683 women and 414 men) from the Lower Silesian voivodeship. Anthropometrical parameters and blood pressure were measured. Blood samples were taken for an examination of lipid profile and fasting glucose level. Genomic DNA was isolated and FTO polymorphism rs9939609 was genotyped.

Results. Male A-allele carriers had significantly higher mean body mass, body mass index (BMI), waistto-hip ratio (WHR), and waist and hip circumferences than men without risk allele. They were also more often diagnosed with obesity on the basis of BMl and central obesity parameters. No such influence was observed in women. There were no significant associations between FTO polymorphism and metabolic syndrome or its components.

Conclusions. Our results suggest a sex-specific association between FTO polymorphism and obesity traits. The occurrence of metabolic syndrome or its components was not related with FTO gene variation in our cohort.
\end{abstract}

Key words: metabolic syndrome, obesity, FTO gene, PURE study

Cite as

Zdrojowy-Wełna A, Bednarek-Tupikowska G, Zatońska K, Kolačkov K, Jokiel-Rokita A, Bolanowski M. The association between FTO gene polymorphism rs 9939609 and obesity is sex-specific in the population of PURE study in Poland Adv Clin Exp Med. 2020;29(1):25-32.

doi:10.17219/acem/111811

DOI

10.17219/acem/111811

Copyright

Copyright by Author(s)

This is an article distributed under the terms of the Creative Commons Attribution Non-Commercial License (http://creativecommons.org/licenses/by-nc-nd/4.0/) 


\section{Background}

The rising prevalence of obesity and overweight has been described as a global pandemic, accounting for about 3.4 million deaths in 2010. ${ }^{1}$ In order to decrease this tendency, we need to understand the pathogenesis of adiposity and its complications, such as diabetes, hypertension and dyslipidemia.

Since 2007, it has been shown that variations in the first intron of the fat mass and obesity-associated (FTO) gene contribute to excessive weight in many populations. ${ }^{2-5}$ However, this relation is race-specific and not all studies have confirmed the influence of FTO gene variation on body mass index (BMI). ${ }^{6,7}$ The association between FTO gene and cardiovascular complications is also controversial. Some authors have shown that risk allele carriers are predisposed to metabolic syndrome (higher fasting glucose, insulin, triglycerides, and lower high-density-lipoprotein (HDL) cholesterol serum levels), ${ }^{8}$ or its components even after BMI adjustment. ${ }^{9-11}$ Others studies found no link between FTO and diabetes ${ }^{12}$ or other metabolic disturbances. ${ }^{4,13}$

The FTO gene is located in chromosome region 16q12.2 and encodes the nucleic acid demethylase. It is expressed in many tissues, most highly in hypothalamic regions responsible for energy homeostasis. ${ }^{14}$ The major substrate for FTO protein is $\mathrm{N}^{6}$-methyladenosine $\left(\mathrm{m}^{6} \mathrm{~A}\right)$ in nuclear RNA. ${ }^{15}$ The $\mathrm{m}^{6} \mathrm{~A}$ is a prevalent internal modification of messenger RNA (mRNA), regulating gene expression ${ }^{16}$; thus, its demethylation plays an important role in mRNA processing. ${ }^{17}$ People with FTO risk alleles are predisposed to obesity probably as a result of impaired central satiety processing and increased food intake ${ }^{18,19}$ together with a preference for high-calorie foods. ${ }^{20,21}$ FTO gene may also be involved in the regulation of adipogenesis, ${ }^{17,22}$ lipolysis ${ }^{23}$ and adipocyte thermogenesis. ${ }^{24}$

Although many previous studies concerned variations in the FTO gene with respect to obesity, there are a few important reasons to perform our analysis. Firstly, the influence of FTO gene on obesity and metabolic complications differs in various ethnic groups. ${ }^{25}$ A recent association analysis in Poland confirmed the correlation between susceptibility loci in intron 1 of the FTO gene with obesity; however, it did not include the aspect of cardiovascular complications. ${ }^{26}$ Other studies conducted in Poland were based on smaller sample sizes ${ }^{13,27}$ or included only specific groups, like children with diabetes ${ }^{28}$ or women with polycystic ovary syndrome (PCOS) ${ }^{29}$ We examined the largest number of subjects from an unselected Polish population for the FTO variation and metabolic syndrome components.

\section{Objectives}

The aim of our study was to assess the association between FTO rs9939609 single nucleotide polymorphism
(SNP) and obesity and metabolic syndrome components in the Polish group from the Prospective Urban Rural Epidemiology (PURE) study.

\section{Material and methods}

\section{Study group and examination protocol}

We enrolled 1,097 subjects (683 women and 414 men) from the Lower Silesian voivodeship in Poland (690 inhabitants of the city of Wrocław and 407 inhabitants of neighboring rural area), aged 30-80 years, who took part in the PURE study in years 2007-2010. The aims and design of the PURE study have been published elsewhere. ${ }^{30}$ Each participant answered the PURE Questionnaire collected by a trained person, providing information about age, social background and medical history (including chronic medication and comorbidities). The physical examination included measurement of height with the subject's head in Frankfurt plane (accuracy of $0.5 \mathrm{~cm}$ ) and weight on calibrated Tanita scales (accuracy of $0.1 \mathrm{~kg}$ ). The BMI was calculated as follows:

$$
\mathrm{BMI}=\frac{\text { weight }[\mathrm{kg}]}{[\text { height }[\mathrm{m}]]^{2}}
$$

The waist circumference was measured with tape, halfway between the lowest rib and the top of the hipbone. The hip circumference was measured with tape, at the widest part of the buttocks. The waist-to-hip ratio (WHR) was calculated as follows:

$$
\text { WHR }=\frac{\text { waist circumference }[\mathrm{cm}]}{\text { hip circumference }[\mathrm{cm}]}
$$

After 10 min of rest, the blood pressure was measured twice on the right arm with the use of Omron HEM-757 apparatus (Osaka, Japan). Blood samples from ulnar vein were taken in the morning after $8 \mathrm{~h}$ of fasting, and centrifuged at $1,000 \times \mathrm{g}$ for $20 \mathrm{~min}$ at $4^{\circ} \mathrm{C}$. Each serum sample was stored at $-80^{\circ} \mathrm{C}$. Total serum cholesterol, triglycerides and HDL cholesterol were measured using standardized methods with the enzymatic assay SPINREACT (Sant Esteve De Bas, Girona, Spain). The level of low-density lipoprotein (LDL) cholesterol was estimated using Friedewald formula:

$$
\begin{aligned}
\text { LDL cholesterol } & =\text { triglycerides }- \text { HDL cholesterol }- \\
& - \text { triglycerides } / 5
\end{aligned}
$$

(in patients with triglycerides concentration lower than $400 \mathrm{mg} / \mathrm{dL}$ ).

Plasma glucose was measured with standardized enzymatic methods using glucose oxidase (Dade Behring GmbH, Marburg, Germany). The metabolic syndrome was diagnosed if 3 or more of the following 5 criteria were met: waist circumference over $102 \mathrm{~cm}$ (men) or $88 \mathrm{~cm}$ (women), blood pressure over 130/85 mm Hg, triglyceride level over $1.7 \mathrm{mmol} / \mathrm{L}$, HDL cholesterol level less than $1.03 \mathrm{mmol} / \mathrm{L}$ 
(men) or $1.29 \mathrm{mmol} / \mathrm{L}$ (women), and fasting blood sugar over 100 mg/dL (National Cholesterol Education Program - Adult Treatment Panel III (NCEP-ATPIII) criteria).

Each participant submitted oral and written consent. The study was approved by Wroclaw Medical University Ethical Committee (approval No. KB 438/2014).

\section{Genotyping}

The FTO gene contains several polymorphic sites. In many populations, obesity susceptibility loci were found in intron 1 of the gene. The rs9939609 variant stays in strong linkage disequilibrium with other polymorphic sites in this intron, which gives the rationale to select this variant for genotyping in our study.

The genomic DNA was extracted from peripheral blood leukocytes in the blood samples according to the protocol of a commercial DNA isolation kit (NucleoMag ${ }^{\circledR} 96$ Blood; Macherey-Nagel GmbH \& Co. KG, Düren, Germany). Polymerase chain reaction (PCR) conditions were optimized and a pair of specific primers was designed (synthesized by Generi Biotech s.r.o., Hradec Králové, Czech Republic) for the amplification and identification of the rs9939609 FTO gene polymorphism:

5'-CACTAACATCAGTTATGCAT-3' - forward primer 5'-CCATTTCTGACTGTTACCTA-3' - reverse primer. Specific fragments of the FTO gene containing polymorphic sites were amplified with PCR using the TaKaRa Taq DNA Polymerase Amplification Kit (Takara Bio Inc., Shiga, Japan). The PCR mix $(20 \mu \mathrm{L})$ contained forward and reverse primers (as above), $1 \times$ PCR buffer containing $1.5 \mathrm{mM} \mathrm{MgCl} 2,200 \mu \mathrm{M}$ dNTPs, 2 units of Taq polymerase, and 200 ng of genomic DNA. Amplification was performed using a TPersonal Thermocycler (Biometra GmbH, Göttingen, Germany) with the following cycle conditions: initial denaturation at $95^{\circ} \mathrm{C}$ for $5 \mathrm{~min}$, followed by 35 cycles of: denaturation at $95^{\circ} \mathrm{C}$ for $30 \mathrm{~s}$, annealing at $55^{\circ} \mathrm{C}$ for $45 \mathrm{~s}$, extension at $72^{\circ} \mathrm{C}$ for $45 \mathrm{~s}$, and final extension at $72^{\circ} \mathrm{C}$ for $5 \mathrm{~min}$. The post-PCR products were purified of excess primers and nucleotides using a mixture of SAP and ExoI enzymes (Thermo Fisher Scientific, Waltham, USA).

The identification of gene polymorphism was performed using the minisequencing method according to the protocol of an ABI PRISM ${ }^{\circledR}$ SNaPshot ${ }^{\mathrm{TM}}$ Multiplex Kit (Thermo Fisher Scientific). The reaction was carried out in the presence of primers extended using single fluorescence-labeled dideoxynucleotide (ddNTP). This reaction consisted of 25 cycles: denaturation at $96^{\circ} \mathrm{C}$ for $10 \mathrm{~s}$, annealing at $50^{\circ} \mathrm{C}$ for $5 \mathrm{~s}$ and extension at $60^{\circ} \mathrm{C}$ for $30 \mathrm{~s}$. The designed specific primer was:

\section{5'TGTCTGAATTATTATTCTAGGTTCCTTGC-} GACTGCTGTGAATTT-3'.

Fluorescently labeled products of the reaction were separated with capillary electrophoresis in ABI PRISM ${ }^{\circledR} 3100$ Genetic Analyzer (Thermo Fisher Scientific) and analyzed by GeneMapper ${ }^{\circledR}$ software v. 4.0 (Thermo Fisher Scientific).

\section{Statistical analysis}

Statistical analysis was performed using STATISTICA v. 12 for Windows (StatSoft Inc., Tulsa, USA). We described variables using elements of descriptive statistics that included the following: minimum and maximum value, mean and standard deviation (SD). Contingency tables were created for qualitative data. The Shapiro-Wilk test was used to verify how well the distribution of the studied characteristics fitted with normal distribution. If the hypothesis of normality was not rejected, then the Student's test or Welch's test was used to verify the equality of means, depending on the hypothesis of equality of variances could be accepted.

The distribution of most of the variables was significantly different from the normal distribution; thus, nonparametric methods were also used to conduct the analysis. The hypotheses of homogeneity (equality) of distributions were verified using the Kolmogorov-Smirnov test and the Mann-Whitney test, depending on the assumption of the Mann-Whitney test could be accepted. We used the $X^{2}$ test to verify the hypothesis of independence between qualitative data. Frequencies of the observed alleles were tested against the Hardy-Weinberg equilibrium. Differences were considered statistically significant at $\mathrm{p}<0.05$.

\section{Results}

We genotyped SNP rs9939609 in 1,097 individuals (683 women and 414 men). The frequency of A-allele (obesity risk allele) among participants was 0.44 and of T-allele - 0.56. Variant frequencies followed the Hardy-Weinberg equilibrium and the genotyping success rates exceeded $98 \%$. Briefly, $20.2 \%$ of the study group were homozygous for A-allele (AA-group), 32.4\% had 2 T-alleles (TT-group) and $47.3 \%$ were heterozygotes (AT-group) - see Table 1. The occurrence of alleles was sex-independent $(p=0.6659)$.

The characteristics of the study group are shown in Table 2. Mean BMI among participants was $28.2 \mathrm{~kg} / \mathrm{m}^{2}$. About $31 \%$ of the group had obesity defined with a BMI over $30 \mathrm{~kg} / \mathrm{m}^{2}$ - similarly in both sex groups, while overweight (BMI $25-29.9 \mathrm{~kg} / \mathrm{m}^{2}$ ) affected $48.6 \%$ of men and $36.6 \%$ of women $\left(\mathrm{p}=4 \times 10^{-5}\right)$. Central obesity according to waist circumference criterion (over $88 \mathrm{~cm}$ in women

Table 1. The frequencies of FTO polymorphism rs9939609 alleles in the study group

\begin{tabular}{|l|c|c|c|}
\multicolumn{1}{|c|}{ Allele } & Whole group & Women & Men \\
\hline AA & $222(20.24 \%)$ & $144(21.08 \%)$ & $78(18.84 \%)$ \\
\hline AT & $519(47.31 \%)$ & $319(46.71 \%)$ & $200(48.31 \%)$ \\
\hline AA + AT & $741(67.55 \%)$ & $463(67.79 \%)$ & $278(67.15 \%)$ \\
\hline TT & $356(32.45 \%)$ & $220(32.21 \%)$ & $136(32.85 \%)$ \\
\hline
\end{tabular}


Table 2. Characteristics of the study group

\begin{tabular}{|c|c|c|c|c|}
\hline Characteristics & Study group & Women & Men & p-value \\
\hline Number of subjects & 1,097 & 683 & 414 & - \\
\hline Age [years], mean $\pm S D$ & $54.20 \pm 9.26$ & $54.38 \pm 8.86$ & $53.98 \pm 9.89$ & $p<0.05^{*}$ \\
\hline $\mathrm{BMI}\left[\mathrm{kg} / \mathrm{m}^{2}\right]$, mean $\pm \mathrm{SD}$ & $28.2 \pm 5.0$ & $28.0 \pm 5.4$ & $28.5 \pm 4.4$ & $p<0.001^{*}$ \\
\hline Waist circumference $[\mathrm{cm}]$, mean $\pm \mathrm{SD}$ & $92.1 \pm 13.9$ & $88.1 \pm 13.4$ & $98.8 \pm 12$ & $p<0.001^{*}$ \\
\hline WHR, mean $\pm S D$ & $0.88 \pm 0.09$ & $0.84 \pm 0.07$ & $0.96 \pm 0.07$ & $p<0.001^{*}$ \\
\hline $\mathrm{SBP}[\mathrm{mm} \mathrm{Hg}]$, mean $\pm \mathrm{SD}$ & $146.6 \pm 21.6$ & $143.0 \pm 21.7$ & $152.4 \pm 20.3$ & $p<0.001^{*}$ \\
\hline $\mathrm{DBP}[\mathrm{mm} \mathrm{Hg}]$, mean $\pm \mathrm{SD}$ & $86.2 \pm 11.3$ & $84.3 \pm 10.7$ & $89.2 \pm 11.7$ & $p<0.001^{*}$ \\
\hline Blood glucose $[\mathrm{mg} / \mathrm{dL}]$, mean \pm SD & $99.4 \pm 21.6$ & $99.3 \pm 21.5$ & $99.7 \pm 21.7$ & $p>0.1^{*}$ \\
\hline Total cholesterol $[\mathrm{mmol} / \mathrm{L}]$, mean $\pm \mathrm{SD}$ & $5.05 \pm 1.02$ & $5.1 \pm 1.0$ & $4.96 \pm 1.05$ & $p=0.01^{* *}$ \\
\hline LDL cholesterol [mmol/L], mean \pm SD & $2.90 \pm 0.92$ & $2.89 \pm 0.93$ & $2.92 \pm 0.92$ & $p=0.448^{* *}$ \\
\hline $\mathrm{HDL}$ cholesterol [mmol/L], mean $\pm \mathrm{SD}$ & $1.50 \pm 0.43$ & $1.60 \pm 0.41$ & $1.34 \pm 0.40$ & $p<0.001^{*}$ \\
\hline Triglycerides $[\mathrm{mmol} / \mathrm{L}]$, mean $\pm \mathrm{SD}$ & $1.44 \pm 0.98$ & $1.36 \pm 0.84$ & $1.58 \pm 1.16$ & $p<0.005^{*}$ \\
\hline
\end{tabular}

* Kolmogorov-Smirnov test; ** Mann-Whitney U test; SD - standard deviation; BMI - body mass index; DBP - diastolic blood pressure, SBP - systolic blood pressure, WHR - waist-to-hip ratio; LDL - low-density lipoprotein; HDL - high-density lipoprotein.

Table 3. FTO polymorphism rs9939609 and anthropometric parameters in the whole study group

\begin{tabular}{|l|c|c|c|c|c|}
\multirow{2}{*}{\multicolumn{1}{c|}{ Characteristic }} & \multicolumn{3}{c|}{ FTO rs9939609 genotype } & \multicolumn{2}{c|}{ p-value $^{*}$} \\
\cline { 2 - 6 } & AA & AT & TT & AA vs TT & AA+ AT vs TT \\
\hline Body mass $[\mathrm{kg}]$, mean \pm SD & $77.65 \pm 16.26$ & $78.15 \pm 17.00$ & $75.7 \pm 14.5$ & 0.1 & 0.1 \\
\hline BMI $\left[\mathrm{kg} / \mathrm{m}^{2}\right]$, mean \pm SD & $28.45 \pm 5.35$ & $28.41 \pm 5.12$ & $27.80 \pm 4.84$ & 0.1 & 0.1 \\
\hline Waist circumference $[\mathrm{cm}]$, mean \pm SD & $92.84 \pm 14.60$ & $92.59 \pm 14.10$ & $91.1 \pm 12.9$ & 0.1 & 0.1 \\
\hline Hip circumference $[\mathrm{cm}]$, mean \pm SD & $104.55 \pm 9.99$ & $104.66 \pm 10.29$ & $103.35 \pm 9.36$ & 0.1 & 0.1 \\
\hline WHR, mean \pm SD & $0.89 \pm 0.098$ & $0.88 \pm 0.09$ & $0.88 \pm 0.09$ & 0.1 & 0.1 \\
\hline
\end{tabular}

* Kolmogorov-Smirnov test; BMI - body mass index; WHR - waist-to-hip ratio; SD - standard deviation.

Table 4. FTO polymorphism rs9939609 and anthropometric parameters in male group

\begin{tabular}{|c|c|c|c|c|c|}
\hline \multirow{2}{*}{ Characteristics } & \multicolumn{3}{|c|}{ FTO rs9939609 genotype } & \multicolumn{2}{|c|}{$p$-value } \\
\hline & AA & AT & TT & AA vs TT & $\mathrm{AA}+\mathrm{AT}$ vs TT \\
\hline Body mass $[\mathrm{kg}]$, mean $\pm \mathrm{SD}$ & $86.76 \pm 14.75$ & $87.82 \pm 16.52$ & $82.38 \pm 12.98$ & $p=0.025^{* *}$ & $p=0.0005^{* * *}$ \\
\hline $\mathrm{BMI}\left[\mathrm{kg} / \mathrm{m}^{2}\right]$, mean $\pm \mathrm{SD}$ & $28.99 \pm 4.63$ & $28.99 \pm 4.52$ & $27.60 \pm 3.96$ & $0.05<p<0.1^{*}$ & $\mathrm{p}<0.01^{*}$ \\
\hline Waist circumference $[\mathrm{cm}]$, mean $\pm \mathrm{SD}$ & $100.80 \pm 12.91$ & $99.86 \pm 12.20$ & $95.99 \pm 10.70$ & $p=0.004^{* *}$ & $p=0.0005^{* * *}$ \\
\hline Hip circumference $[\mathrm{cm}]$, mean \pm SD & $103.33 \pm 7.70$ & $103.73 \pm 8.50$ & $101.26 \pm 7.60$ & $p>0.1^{*}$ & $p<0.005^{*}$ \\
\hline WHR, mean $\pm S D$ & $0.97 \pm 0.08$ & $0.96 \pm 0.07$ & $0.94 \pm 0.07$ & $p>0.1^{*}$ & $0.05<p<0.1^{*}$ \\
\hline
\end{tabular}

* Kolmogorov-Smirnov test; ** Student's t-test; ***Welch's test; FTO - obesity-associated gene; SD - standard deviation; BMI - body mass index; WHR - waist-to-hip ratio.

and $102 \mathrm{~cm}$ in men) was diagnosed in $45.3 \%$ of women and $35.6 \%$ of men ( $\mathrm{p}=0.0017)$. According to WHR criterion, central obesity was present in $39 \%$ of women (WHR > 0.85 ) and $81.8 \%$ of men (WHR > 0.9). In our examination, $42.9 \%$ of men and $25.6 \%$ of women had blood pressure over $140 / 90 \mathrm{~mm} \mathrm{Hg}$, indicating hypertension $\left(\mathrm{p}<10^{-5}\right)$. Impaired fasting glucose $(100-125 \mathrm{mg} / \mathrm{dL})$ occurred in $31.9 \%$ of the participants, while hyperglycemia suggestive for diabetes (>126 mg/dL) was present in $6.6 \%$ of the study group (no difference between men and women, $\mathrm{p}=0.948$ ). Mean total and HDL cholesterol levels were higher in women than in men, while men had higher levels of triglycerides in the blood. There was no significant difference in LDL cholesterol levels between sex groups. Three hundred eighty-two participants ( $37 \%$ of the group) fulfilled the NCEP-ATPIII criteria for the presence of metabolic syndrome, and there was no difference between men and women $(\mathrm{p}=0.68)$.

There were no significant associations between obesity parameters and FTO rs9939609 polymorphism in the whole study group (Table 3 ). However, when we analyzed men and women separately, obesity traits were significantly associated ( $\mathrm{p}<0.01$ after adjustment for multiple testing) with the occurrence of A-allele in men (Table 4). The differences were present both in the recessive and co-dominant model. A-allele carriers had higher mean 
Table 5. FTO polymorphism rs9939609 and anthropometric parameters in female group

\begin{tabular}{|c|c|c|c|c|c|}
\hline \multirow{2}{*}{ Characteristics } & \multicolumn{3}{|c|}{ FTO rs9939609 genotype } & \multicolumn{2}{|c|}{ p-value* } \\
\hline & AA & AT & TT & AA vs TT & $\mathrm{AA}+\mathrm{AT}$ vs TT \\
\hline Body mass [kg], mean $\pm S D$ & $72.71 \pm 14.88$ & $72.07 \pm 14.30$ & $71.57 \pm 13.90$ & $p>0.1$ & $p>0.1$ \\
\hline $\mathrm{BMI}\left[\mathrm{kg} / \mathrm{m}^{2}\right]$, mean $\pm \mathrm{SD}$ & $28.17 \pm 5.69$ & $28.05 \pm 5.44$ & $27.93 \pm 5.30$ & $p>0.1$ & $p>0.1$ \\
\hline Waist circumference $[\mathrm{cm}]$, mean $\pm \mathrm{SD}$ & $88.53 \pm 13.60$ & $88.02 \pm 13.30$ & $88.04 \pm 13.30$ & $p>0.1$ & $p>0.1$ \\
\hline Hip circumference $[\mathrm{cm}]$, mean $\pm S D$ & $105.20 \pm 11.02$ & $105.25 \pm 11.25$ & $104.64 \pm 10.10$ & $p>0.1$ & $p>0.1$ \\
\hline WHR, mean $\pm S D$ & $0.84 \pm 0.07$ & $0.83 \pm 0.07$ & $0.84 \pm 0.07$ & $p>0.1$ & $p>0.1$ \\
\hline
\end{tabular}

* Kolmogorov-Smirnov test; FTO - obesity-associated gene; SD - standard deviation; BMI - body mass index; WHR - waist-to-hip ratio.

Table 6. FTO polymorphism rs9939609 and blood pressure measurements

\begin{tabular}{|c|c|c|c|c|c|}
\hline \multirow{2}{*}{ Parameter } & \multicolumn{3}{|c|}{ FTO rs9939609 genotype } & \multicolumn{2}{|c|}{$p$-value } \\
\hline & AA & AT & $\mathrm{TT}$ & AA vs TT & $A A+A T$ vs TT \\
\hline SBP $[\mathrm{mm} \mathrm{Hg}]$ - whole group, mean \pm SD & $145.4 \pm 20.5$ & $145.7 \pm 21.4$ & $148.5 \pm 22.3$ & $0.1^{*}$ & $0.1^{*}$ \\
\hline $\mathrm{DBP}[\mathrm{mm} \mathrm{Hg}]$ - whole group, mean $\pm \mathrm{SD}$ & $85.3 \pm 10.4$ & $85.9 \pm 11.5$ & $87.2 \pm 11.6$ & $0.1^{*}$ & $0.1^{*}$ \\
\hline $\mathrm{SBP}[\mathrm{mm} \mathrm{Hg}]-$ men, mean $\pm \mathrm{SD}$ & $152.6 \pm 17.1$ & $151.2 \pm 21.0$ & $153.8 \pm 20.7$ & $0.66^{* *}$ & $0.3^{* *}$ \\
\hline $\mathrm{DBP}[\mathrm{mm} \mathrm{Hg}]-$ men, mean $\pm \mathrm{SD}$ & $87.0 \pm 10.1$ & $89.3 \pm 11.6$ & $90.4 \pm 12.5$ & $0.05^{* *}$ & $0.16^{* *}$ \\
\hline $\mathrm{SBP}[\mathrm{mm} \mathrm{Hg}]$ - women, mean $\pm \mathrm{SD}$ & $141.5 \pm 21.2$ & $142.3 \pm 20.8$ & $145.2 \pm 22.6$ & $0.1^{*}$ & $0.1^{*}$ \\
\hline $\mathrm{DBP}[\mathrm{mm} \mathrm{Hg}]$ - women, mean $\pm \mathrm{SD}$ & $84.2 \pm 10.5$ & $83.7 \pm 10.9$ & $85.2 \pm 10.5$ & $0.1^{*}$ & $0.1^{*}$ \\
\hline
\end{tabular}

* Kolmogorov-Smirnov test; ** Shapiro-Wilk test; SBP - systolic blood pressure; DBP - diastolic blood pressure.

Table 7. FTO polymorphism rs9939609 and lipid levels

\begin{tabular}{|c|c|c|c|c|c|}
\hline \multirow{2}{*}{ Parameter } & \multicolumn{3}{|c|}{ FTO rs9939609 genotype } & \multicolumn{2}{|c|}{$p$-value* } \\
\hline & AA & AT & $\mathrm{TT}$ & AA vs TT & $A A+A T$ vs TT \\
\hline Total cholesterol in whole group [mmol/L], mean \pm SD & $4.95 \pm 1.02$ & $5.06 \pm 1.00$ & $5.09 \pm 1.05$ & 0.1 & 0.1 \\
\hline LDL cholesterol in whole group [mmol/L], mean $\pm S D$ & $2.82 \pm 0.92$ & $2.91 \pm 0.91$ & $2.93 \pm 0.95$ & $0.05<p<0.1$ & 0.1 \\
\hline $\mathrm{HDL}$ cholesterol in whole group [mmol/L], mean $\pm \mathrm{SD}$ & $1.47 \pm 0.42$ & $1.51 \pm 0.43$ & $1.53 \pm 0.43$ & 0.1 & 0.1 \\
\hline Triglycerydes in whole group [mmol/L], mean $\pm S D$ & $1.48 \pm 0.89$ & $1.45 \pm 1.04$ & $1.41 \pm 0.94$ & 0.1 & 0.1 \\
\hline Total cholesterol in women [mmol/L], mean \pm SD & $5.07 \pm 1.05$ & $5.12 \pm 0.97$ & $5.10 \pm 1.02$ & 0.1 & 0.1 \\
\hline $\mathrm{LDL}$ cholesterol in women $[\mathrm{mmol} / \mathrm{L}]$, mean $\pm \mathrm{SD}$ & $2.84 \pm 0.94$ & $2.89 \pm 0.89$ & $2.90 \pm 0.98$ & 0.1 & 0.1 \\
\hline $\mathrm{HDL}$ cholesterol in women [mmol/L], mean $\pm \mathrm{SD}$ & $1.58 \pm 0.41$ & $1.61 \pm 0.39$ & $1.62 \pm 0.44$ & 0.1 & 0.1 \\
\hline Triglycerydes in women [mmol/L], mean $\pm S D$ & $1.44 \pm 0.89$ & $1.37 \pm 0.86$ & $1.30 \pm 0.76$ & 0.1 & 0.1 \\
\hline Total cholesterol in men [mmol/L], mean \pm SD & $4.70 \pm 0.91$ & $4.96 \pm 1.05$ & $5.09 \pm 1.11$ & $0.05<p<0.1$ & 0.1 \\
\hline $\mathrm{LDL}$ cholesterol in men $[\mathrm{mmol} / \mathrm{L}]$, mean $\pm \mathrm{SD}$ & $2.77 \pm 0.87$ & $2.93 \pm 0.95$ & $2.96 \pm 0.89$ & $0.05<p<0.1$ & 0.1 \\
\hline $\mathrm{HDL}$ cholesterol in men $[\mathrm{mmol} / \mathrm{L}]$, mean $\pm \mathrm{SD}$ & $1.26 \pm 0.34$ & $1.35 \pm 0.43$ & $1.37 \pm 0.38$ & $0.05<p<0.1$ & 0.1 \\
\hline Triglycerydes in men [mmol/L], mean $\pm S D$ & $1.56 \pm 0.86$ & $1.57 \pm 1.27$ & $1.59 \pm 1.15$ & 0.1 & 0.1 \\
\hline
\end{tabular}

* Kolmogorov-Smirnov test; LDL - low-density lipoprotein; HDL - high-density lipoprotein; SD - standard deviation.

BMI (AA-group and AT-group - $28.99 \mathrm{~kg} / \mathrm{m}^{2}$, TT-group $\left.-27.6 \mathrm{~kg} / \mathrm{m}^{2}, \mathrm{p}<0.01\right)$ and were more often diagnosed with obesity defined with BMI $>30 \mathrm{~kg} / \mathrm{m}^{2}$ (37\% of AA-group and $24 \%$ of TT-group, $\mathrm{p}=0.04$ ). Male A-allele carriers had higher mean waist circumference and WHR and they were more often diagnosed with central obesity than men without risk allele (44\% of AA-group and $28 \%$ of TT-group had waist circumference over $102 \mathrm{~cm}, \mathrm{p}=0.02 ; 88 \%$ of AA group and 76\% of TT group had WHR $>0.9, \mathrm{p}=0.023$ ). We did not observe any significant associations between FTO polymorphism and obesity traits in the female group (Table 5). In order to find a possible reason why FTO polymorphism had a weaker effect on obesity in women, we divided the female group on the basis of menopausal status and age, but this did not significantly influence the results (data not shown).

We also analyzed the association between FTO rs9939609 polymorphism and blood pressure measurements, lipid and glucose levels in the blood, but there were no significant associations (Tables 6-8). The associations remained insignificant also in separate analyses in men and women. The metabolic syndrome occurred more frequently in risk-allele groups, but the associations were statistically insignificant (Table 9). 
Table 8. FTO polymorphism rs9939609 and glucose level

\begin{tabular}{|l|c|c|c|c|c|}
\hline \multirow{2}{*}{\multicolumn{1}{c|}{ Parameter }} & \multicolumn{3}{c|}{ FTO rs9939609 genotype } & \multicolumn{3}{c|}{ p-value* } \\
\cline { 2 - 6 } & AA & AT & TT & AA vs TT & AA + AT vs TT \\
\hline Glucose level in whole study group $[\mathrm{mg} / \mathrm{dL}]$, mean \pm SD & $101.7 \pm 31.4$ & $99.4 \pm 19.5$ & $98.3 \pm 16.8$ & 0.1 & 0.1 \\
\hline Glucose level in women $[\mathrm{mg} / \mathrm{dL}]$, mean \pm SD & $100.5 \pm 27.5$ & $99.5 \pm 21.0$ & $98.2 \pm 17.6$ & 0.1 & 0.1 \\
\hline Glucose level in men $[\mathrm{mg} / \mathrm{dL}]$, mean \pm SD & $104.0 \pm 37.5$ & $99.2 \pm 16.0$ & $98.5 \pm 15.5$ & 0.1 & 0.1 \\
\hline
\end{tabular}

* Kolmogorov-Smirnov test; SD - standard deviation.

Table 9. The occurrence of metabolic syndrome in study group according to FTO polymorphism rs9939609

\begin{tabular}{|l|c|c|c|c|c|}
\hline \multirow{2}{*}{\multicolumn{1}{c|}{ Parameter }} & \multicolumn{3}{c|}{ FTO rs9939609 genotype } & \multicolumn{3}{c|}{ p-value* } \\
\cline { 2 - 6 } & AA & AT & TT & AA vs TT & AA + AT vs TT \\
\hline Frequency of metabolic syndrome in whole study group & $40.1 \%$ & $37.4 \%$ & $35.4 \%$ & 0.27 & 0.39 \\
\hline Frequency of metabolic syndrome in female group & $38 \%$ & $38 \%$ & $37 \%$ & 0.96 & 0.78 \\
\hline Frequency of metabolic syndrome in male group & $43 \%$ & $36 \%$ & $33 \%$ & 0.33 & 0.29 \\
\hline
\end{tabular}

${ }^{*} x^{2}$ test.

\section{Discussion}

The frequency of obesity-risk A-allele in our group was 0.44, which remained in accordance to that of other European populations. ${ }^{3,25}$ The analyzed FTO SNP rs 9939609 had, together with rs1558902, rs1421085, rs9930506, and rs12149832, the strongest influence on obesity phenotype in the recent association study in Polish population. These SNPs are located in intron 1 and stay in almost complete linkage disequilibrium (LD) $\left(\left|\mathrm{D}^{\prime}\right|>0.98, \mathrm{r}^{2}>0.80\right){ }^{26}$

Many studies confirmed that the FTO gene variation predisposes to excessive weight. This association varies significantly in different ethnic groups. ${ }^{2-5}$ Nonetheless, it remains the strongest genetic determinant of common obesity known so far, with an estimated population risk of $22 \% .^{2}$ In this context, we have confirmed such an association in the male population of Lower Silesia in Poland. However, our most interesting result is the significant difference in the influence of FTO polymorphism on obesity traits between men and women in our cohort. Male A-allele carriers had higher mean BMI, waist circumference and WHR, and were more often diagnosed with obesity on the basis of all those criteria than men without genetic risk factor. We did not observe such associations in the female group. Sex-dependent contribution of FTO gene on obesity is a novel finding. To our knowledge, there are only 2 previous studies, 1 in the Polish and 1 in the Mexican population, where sex-specific differences have been shown. Sobalska-Kwapis et al. demonstrated a strong association of $F T O$ intronic variants in block 8 with overweight in a group of men only; however, this sex difference was no longer valid in the case of obesity. When authors considered obesity and overweight groups together, there were only 8 statistically significant SNPs in women comparing with $27 \mathrm{SNPs}$ in men. It has been also revealed in this study that obesity-associated SNPs had a different inheritance model in men (recessive) than in women (dominant). ${ }^{26}$ In the Mexican population, Saldaña-Alvarez et al. have shown, in turn, that 2 FTO SNPs were specifically associated in men under a dominant model, while 3 were associated with women under additive and recessive models. ${ }^{31}$ Together with our results, this highlights the need to consider sex as an important factor modulating FTO genetic association with overweight and obesity. The outcomes of our study and the one of and Sobalska-Kwapis et al. suggest that in Polish women, obesity is less influenced by FTO polymorphism than in men. ${ }^{26}$

To further explore this problem, we analyzed the FTO influence on obesity in female subgroups according to menopausal status and age, but it did not change our results. There are suggestions that the association between FTO gene and obesity is age-dependent. ${ }^{32}$ We also know that many other factors (socioeconomic, cultural, environmental, psychological) play an important role in such a complex trait as body mass. In our other publication, we presented a list of important environmental determinants of obesity in the population of PURE study in Poland. ${ }^{33}$ Some of those factors (like rural inhabitancy, unemployment and stress) had a greater impact on body mass than $F T O$ polymorphism, particularly in women. We can presume that environmental factors play a more important role in the pathogenesis of female obesity in our study, which blurs the role of FTO gene. Moreover, other regions in genome may regulate overweight/obesity in a sex-dependent manner. It has been shown that FTO sequences are functionally connected with other genes, for example homeobox gene $I R X .{ }^{34}$ Landgraf et al. reported that $F T O$ variants affected adipocyte-specific expression of IRX5 and $I R X 3 .{ }^{35}$ There are more studies needed in this area with a distinction between men and women.

To our knowledge, this is the most representative Polish study, in which participants were examined for FTO polymorphism and metabolic syndrome components. Previous studies in Poland suggested that the variation in the FTO gene was related to some metabolic disturbances indicative 
of insulin resistance. For example, Łuczyński et al. have shown that children with AA genotype rs9939609 had higher values of blood pressure (systolic blood pressure (SBP) and diastolic blood pressure (DBP)), triglycerides, fasting insulin, and homeostatic model assessment - insulin resistance (HOMA-IR) index, although only the latter was not attenuated after adjusting for BMI. ${ }^{36}$ In another Polish study consisting of women with PCOS, there was an association between the occurrence of risk allele and lower insulin sensitivity, but it was mediated by adiposity. ${ }^{29}$ The recent analysis of 425 women from West Pomeranian voivodeship revealed that AA homozygotes of FTO rs9939609 presented a higher risk of fasting hyperglycemia than those with at least $1 \mathrm{~T}$ allele, but no associations were found in the case of lipids, blood pressure or waist size. ${ }^{27}$ In a study concerning other FTO polymorphism - rs9930506 in 442 Polish adults, there was no link between this genetic variation and lipid disturbances or higher fasting glucose level. ${ }^{13}$ Recently, Ślęzak et al. presented a study where FTO gene variation was related to single metabolic disturbances in a homogenous male group, but the risk of metabolic syndrome was not increased in risk allele carriers. ${ }^{37}$ In our analysis, we have found no association between carrying FTO rs9939609 risk allele and the onset of metabolic syndrome or its components in men and women from Lower Silesia.

In the context of mentioned studies, we can presume that the FTO influence on metabolic disturbances in Polish population is secondary to its influence on adiposity. Because the link with obesity was not very strong in our group, the association with metabolic syndrome components could not be revealed. Many studies in other countries also suggest that FTO gene variation modifies metabolic disturbances only indirectly through adiposity. For example, the analyses of very big European populations by Frayling et al. and Freathy et al. supported this thesis. ${ }^{3,8}$ However, there are also studies showing that the influence of FTO variation on diabetes onset, age at diagnosis or even diabetes-related complications did not disappear after BMI adjustment. ${ }^{38-40}$ The latter work was performed in the Czech population, which is genetically similar to Poles.

The association between FTO gene and metabolic traits may be explained in different ways. First, it can be only an effect of adiposity. Our results support this thesis - if the influence on obesity is weak, there are consequently no associations with metabolic traits. However, the mentioned works showing that diabetes-related complications are associated with FTO independently of BMI may suggest other mechanism of FTO gene action on metabolism. The expression in different tissues and regulatory role of FTO gene (FTO protein is a nucleic acid demethylase) allows it to be involved in pathogenesis of different disturbances. More studies are needed to explain the exact role of FTO gene in metabolism.

There were a few limitations of our study. Firstly, our results come from cross-sectional analysis, while longitudinal study is more suitable to draw conclusions about obesity and its complications. However, there is an ongoing observation of our cohort and we plan to analyze results of the follow-up after a few years. Secondly, our cohort is not strictly population-based, with some possible snowball sampling biases (according to the PURE study design, people were allowed to register themselves voluntarily in selected urban and rural districts). In other Polish studied, minor allele frequency (MAF) of FTO rs9939609 were higher (Łuczyński et al. ${ }^{36}-0.49$, Sobalska-Kwapis et al. ${ }^{26}-0.69$ ). This may be the reason why the associations between FTO risk allele and obesity traits were weaker in our cohort than in other studies. Another important factor is that our cohort was older than in most Polish studies and we know that in the older age genetic influence on obesity is blurred by environmental factors. Nevertheless, our results stay in accordance with other studies from Poland and Europe and we were able to detect sex-specific difference of FTO influence on obesity, which is a novel and interesting finding. More studies in this area are needed.

\section{ORCID iDs}

Aleksandra Zdrojowy-Wełna (D) https://orcid.org/0000-0001-5640-1928 Grażyna Bednarek-Tupikowska (1) https://orcid.org/0000-0002-8891-6202 Katarzyna Zatońska (D) https://orcid.org/0000-0002-3772-5588 Katarzyna Kolačkov (D) https://orcid.org/0000-0003-4570-0054 Alicja Jokiel-Rokita (D) https://orcid.org/0000-0002-9552-6712 Marek Bolanowski (D) https://orcid.org/0000-0003-4645-967X

\section{References}

1. Lim SS, Vos T, Flaxman AD, et al. A comparative risk assessment of burden of disease and injury attributable to 67 risk factors and risk factor clusters in 21 regions, 1990-2010: A systematic analysis for the Global Burden of Disease Study 2010. Lancet. 2012;380(9859):2224-2260.

2. Dina C, Meyre D, Gallina S, et al. Variation in FTO contributes to childhood obesity and severe adult obesity. Nat Genet. 2007;39(6):724726.

3. Frayling TM, Timpson NJ, Weedon $\mathrm{MN}$, et al. A common variant in the FTO gene is associated with body mass index and predisposes to childhood and adult obesity. Science. 2007;316(5826):889-894.

4. Chang Y-C, Liu P-H, Lee W-J, et al. Common variation in the fat mass and obesity-associated (FTO) gene confers risk of obesity and modulates BMI in the Chinese population. Diabetes. 2008;57(8):2245-2252.

5. Adeyemo A, Chen G, Zhou J, et al. FTO genetic variation and association with obesity in West Africans and African Americans. Diabetes. 2010;59(6):1549-1554.

6. Ohashi J, Naka I, Kimura R, et al. FTO polymorphisms in oceanic populations. J Hum Genet. 2007;52(12):1031-1035.

7. Li H, Wu Y, Loos RJF, et al. Variants in the fat mass and obesity-associated (FTO) gene are not associated with obesity in a Chinese Han population. Diabetes. 2008;57(1):264-268.

8. Freathy RM, Timpson NJ, Lawlor DA, et al. Common variation in the FTO gene alters diabetes-related metabolic traits to the extent expected given its effect on BMI. Diabetes. 2008;57(5):1419-1426.

9. Hakanen M, Raitakari OT, Lehtimäki T, et al. FTO genotype is associated with body mass index after the age of seven years but not with energy intake or leisure-time physical activity. J Clin Endocrinol Metab. 2009;94(4):1281-1287.

10. Shimaoka I, Kamide K, Ohishi M, et al. Association of gene polymorphism of the fat-mass and obesity-associated gene with insulin resistance in Japanese. Hypertens Res. 2010;33(3):214-218.

11. Rees SD, Islam M, Hydrie MZI, et al. An FTO variant is associated with type 2 diabetes in South Asian populations after accounting for body mass index and waist circumference: An FTO variant in South Asian populations. Diabet Med. 2011;28(6):673-680. 
12. Song Y, You N, Hsu Y-H, et al. FTO polymorphisms are associated with obesity but not diabetes risk in postmenopausal women. Obesity (Silver Spring). 2008;16(11):2472-2480.

13. Wrzosek M, Zakrzewska A, Ruczko L, Jabłonowska-Lietz B, Nowicka G. Association between rs9930506 polymorphism of the fat mass and obesity-associated (FTO) gene and onset of obesity in Polish adults. Indian J Med Res. 2016;143(3):281-287.

14. Gerken T, Girard CA, Tung Y-CL, et al. The obesity-associated FTO gene encodes a 2-oxoglutarate-dependent nucleic acid demethylase. Science. 2007;318(5855):1469-1472.

15. Jia G, Fu Y, Zhao X, et al. N6-methyladenosine in nuclear RNA is a major substrate of the obesity-associated FTO. Nat Chem Biol. 2011; 7(12):885-887.

16. Dominissini D, Moshitch-Moshkovitz S, Schwartz S, et al. Topology of the human and mouse m6A RNA methylomes revealed by m6Aseq. Nature. 2012;485(7397):201-206.

17. Zhao X, Yang Y, Sun B-F, et al. FTO-dependent demethylation of N6-methyladenosine regulates mRNA splicing and is required for adipogenesis. Cell Res. 2014;24(12):1403-1419.

18. Melhorn SJ, Askren MK, Chung WK, et al. FTO genotype impacts food intake and corticolimbic activation. Am J Clin Nutr. 2018;107(2):145-154.

19. Karra E, O'Daly OG, Choudhury Al, et al. A link between FTO, ghrelin, and impaired brain food-cue responsivity. J Clin Invest. 2013;123(8): 3539-3551.

20. Cecil JE, Tavendale R, Watt P, Hetherington MM, Palmer CN. An obesity-associated FTO gene variant and increased energy intake in children. N Engl J Med. 2008;359(24):2558-2566.

21. Kühn AB, Feis D-L, Schilbach $L$, et al. FTO gene variant modulates the neural correlates of visual food perception. Neuroimage. 2016; 128:21-31.

22. Merkestein M, Laber S, McMurray F, et al. FTO influences adipogenesis by regulating mitotic clonal expansion. Nat Commun. 2015;6: 6792-6801.

23. Wahlen K, Wåhlén K, Sjölin E. The common rs9939609 gene variant of the fat mass-and obesity-associated gene FTO is related to fat cell lipolysis. J Lipid Res. 2008;49(6):607-611.

24. Claussnitzer M, Dankel SN, Kim K-H, et al. FTO obesity variant circuitry and adipocyte browning in humans. N Engl J Med. 2015;373(10): 895-907.

25. Peng S, Zhu Y, Xu F, Ren X, Li X, Lai M. FTO gene polymorphisms and obesity risk: A meta-analysis. BMC Med. 2011;9:71-86.

26. Sobalska-Kwapis M, Suchanecka A, Słomka M, Siewierska-Górska A, Kępka E, Strapagiel D. Genetic association of FTO/IRX region with obesity and overweight in the Polish population. PLoS One. 2017; 12(6):e0180295. https://doi.org/10.1371/journal.pone.0180295

27. Szkup M, Owczarek AJ, Schneider-Matyka D, Brodowski J, Łój B, Grochans E. Associations between the components of metabolic syndrome and the polymorphisms in the peroxisome proliferatoractivated receptor gamma (PPAR- $\gamma$ ), the fat mass and obesity-associated (FTO), and the melanocortin-4 receptor (MC4R) genes. Aging (Albany NY). 2018;10(1):72-82.
28. Łuczyński W, Fendler W, Ramatowska A, et al. Polymorphism of the FTO gene influences body weight in children with type 1 diabetes without severe obesity. Int J Endocrinol. 2014;2014:630712.

29. Kowalska I, Malecki MT, Straczkowski M, et al. The FTO gene modifies weight, fat mass and insulin sensitivity in women with polycystic ovary syndrome, where its role may be larger than in other phenotypes. Diabetes Metab. 2009;35(4):328-331.

30. Teo K, Chow CK, Vaz M, Rangarajan S, Yusuf S; PURE InvestigatorsWriting Group. The Prospective Urban Rural Epidemiology (PURE) study: Examining the impact of societal influences on chronic noncommunicable diseases in low-, middle-, and high-income countries. Am Heart J. 2009;158(1):1-7.

31. Saldaña-Alvarez Y, Salas-Martínez MG, García-Ortiz H, et al. Gender-dependent association of FTO polymorphisms with body mass index in Mexicans. PLoS One. 2016;11(1):e0145984. doi:10.1371/journal. pone.0145984

32. Jess T, Zimmermann E, Kring SIl, et al. Impact on weight dynamics and general growth of the common FTO rs9939609: A longitudinal Danish cohort study. Int J Obes (Lond). 2008;32(9):1388-1394.

33. Zdrojowy-Wełna A, Zatońska K, Bednarek-Tupikowska G, et al. Determinants of obesity in population of PURE study from Lower Silesia. Endokrynol Pol. 2018;69(6):644-652. doi:10.5603/EP.a2018.0061

34. Smemo S, Tena JJ, Kim K-H, et al. Obesity-associated variants within FTO form long-range functional connections with IRX3. Nature. 2014;507(7492):371-375.

35. Landgraf K, Scholz M, Kovacs P, Kiess W, Körner A. FTO obesity risk variants are linked to adipocyte IRX3 expression and BMI of children: Relevance of FTO variants to defend body weight in lean children? PLoS One. 2016;11(8):e0161739. doi:10.1371/journal.pone.0161739

36. Łuczyński W, Zalewski G, Bossowski A. The association of the FTO rs9939609 polymorphism with obesity and metabolic risk factors for cardiovascular diseases in Polish children. J Physiol Pharmacol. 2012;63(3):241-248.

37. Ślęzak R, Leszczyński P, Warzecha M, Łaczmański L, Misiak B. Assessment of the FTO gene polymorphisms in male patients with metabolic syndrome. Adv Clin Exp Med. 2018;27(11):1581-1585.

38. Legry V, Cottel D, Ferrières J, et al. Effect of an FTO polymorphism on fat mass, obesity, and type 2 diabetes mellitus in the French MONICA study. Metabolism. 2009;58(7):971-975.

39. Kalnina I, Zaharenko L, Vaivade I, et al. Polymorphisms in FTO and near TMEM18 associate with type 2 diabetes and predispose to younger age at diagnosis of diabetes. Gene. 2013;527(2):462-468.

40. HubacekJA,DlouhaD, Klementova M,LanskaV,NeskudlaT,PelikanovaT. The FTO variant is associated with chronic complications of diabetes mellitus in Czech population. Gene. 2018;642:220-224. 